Title: Flavour capsule cigarettes continue to experience strong global growth

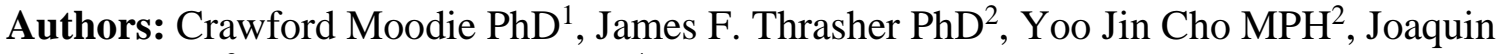
Barnoya $\mathrm{MD}^{3}$, Frank Chaloupka $\mathrm{PhD}^{4}$

\title{
Affiliations:
}

${ }^{1}$ Institute for Social Marketing, School of Health Sciences and Sport, University of Stirling, Stirlingshire FK9 4LA

${ }^{2}$ Department of Health Promotion, Education, and Behavior, Arnold School of Public Health, University of South Carolina, Columbia, US.

${ }^{3}$ Unidad de Cirugia Cardiovascular de Guatemala, Ciudad de Guatemala, Guatemala.

${ }^{4}$ Department of Economics, Institute for Health Research and Policy, University of Illinois at Chicago, Chicago, Illinois, USA

Corresponding author: Crawford Moodie, Institute for Social Marketing, School of Health Sciences and Sport, University of Stirling, Stirlingshire FK9 4LA. Email:

c.s.moodie@stir.ac.uk, Tel: 0044 (0)1786 466456

This article has been accepted for publication in Tobacco Control following peer review. The definitive copyedited, typeset version Moodie C, Thrasher JF, Cho YJ, et al Flavour capsule cigarettes continue to experience strong global growth Tobacco Control is available online at: $\underline{\text { https://doi.org/10.1136/tobaccocontrol-2018-054711 }}$ 


\section{Flavour capsule cigarettes continue to experience strong global growth}

Cigarettes with flavour-changing capsules in the filter, a continuing success story for tobacco companies, have grown exponentially since being introduced in 2007. The global capsule market is estimated to be 150 billion sticks in $2017 .{ }^{1}$ We provide an update on the capsule market since $2014 .^{2}$ From this time capsule cigarettes have been introduced in new markets in Europe (Croatia, Spain), Africa (Tunisia), Latin America (Bolivia, Ecuador, Uruguay) and Asia (China, India, Philippines, Thailand, Vietnam). ${ }^{3}$ They are the fastest growing segment of the combustible market, ${ }^{4}$ with market share increasing between 2014 and 2017 in 52 of the 67 countries where they are sold and monitored by tobacco analyst Euromonitor. ${ }^{3}$ These products now have market share greater than $10 \%$ in four European countries (UK, Hungary, Ireland, Poland), and have increased $12 \%$ in the Middle East and Africa. ${ }^{1}$ The five most popular capsule markets remain in Latin America (see Figure 1), with market share increasing by at least $40 \%$ in each of these countries since 2014 .

The capsule segment offers considerable variety. These cigarettes have either one or two flavour capsules in the filter (the latter reported to be driving growth in some markets ${ }^{5}$ ), with packs containing up to five different flavours ${ }^{6}$ (Figure 2 ). There are now myriad flavours used, including variations of mint (e.g. wild mint, strawberry mint) and some inspired by fruit (e.g. orange peel, mango, cucumber) or beverages and cocktails (e.g. green tea, whisky, mojito). ${ }^{7}$ Tobacco industry journals report a demand for new flavours, ${ }^{8}$ as well as an interest in non-flavour options, with water capsules recently used in some countries to modify the taste through cooling rather than imparting a flavour. ${ }^{9}$ Since 2014 , flavour capsules have also become available in filters for roll-your-own and make-your-own cigarettes, as well as cigars, cigarillos and heated tobacco products. ${ }^{10-12}$

The retail environment is important in promoting capsule cigarettes (Figure 3), even in countries which have banned the display of tobacco products. Following a display ban in the UK, for instance, tobacco industry representatives have encouraged small retailers to promote certain brands of capsule cigarettes. ${ }^{13}$ The packaging has also been key to the marketing of capsule cigarettes. As more countries adopt large pictorial health warnings, which compete with the brand imagery on packs, and introduce plain (standardised) packaging, this would be expected to slow the growth of capsule cigarettes. However, tobacco industry journals suggest that while larger health warnings and plain packaging reduce the opportunity for brand promotion and make brand-building more difficult, filter characteristics still allow for brand differentiation and marketing. ${ }^{9,14,15}$ In Australia and the UK, tobacco companies introduced several new capsule variants after plain packaging was fully implemented ${ }^{16}$ - at least five new capsule variants were brought to market in the UK in 2018 alone.

Despite the success of this product innovation, there remains a dearth of research on capsule cigarettes. Nevertheless, existing research with adult smokers in the UK, US, and Australia consistently show a preference for capsules among young adults, ${ }^{11,17,18}$ and more than half of 12-17 year old past-month smokers in Australia reported having tried a capsule cigarette. ${ }^{19}$ Taste, choice of flavours, enjoyment from clicking the capsule, stylishness, and lower perceived harm appear key reasons for using capsule cigarettes. ${ }^{11,17-21}$ Other studies have found that capsule cigarettes are viewed favourably among non-smokers and thought to encourage experimentation, and are perceived as a "cool invention" that is fun and appealing for adolescents and newer smokers. ${ }^{20,22,23}$

Regulators have been slow to respond to the threat of capsule cigarettes. As of 2018 only Canada, Ethiopia, Senegal, and Uganda had banned flavoured tobacco products, although they will be banned in Brazil by March 2020 and, as a result of the Tobacco 
Products Directive, across much of Europe by May $2020 ;{ }^{24}$ these bans do not cover nonflavour capsules, such as the cigarettes with water capsules (e.g. Camel North Aqua Filter) introduced in 2017 in Canada after the flavour ban. ${ }^{25}$ If flavour bans are not introduced elsewhere, then there is little reason to expect anything other than the continued growth of products that put the "fun" back into combustibles. ${ }^{20}$

\section{What this paper adds}

- Global sales of cigarettes with flavour capsules in the filter have continued to grow since 2014

- There are myriad flavours for capsule cigarettes, with capsules now available for roll-your-own and make-your-own cigarettes, as well as cigars, cigarillos and heated tobacco products

- Few studies have explored capsule cigarettes, but existing research suggests that they are particularly appealing to younger people

- While few countries ban capsule cigarettes, they will be banned across much of Europe by 2020

Funding None.

Competing interests None declared.

Author contributions CM drafted the article, with help from JFT, YJC, JB and FC. All authors approved the final version.

Provenance and peer review Not commissioned; externally peer reviewed. 


\section{References}

$1 \quad$ Meredith P. Outstanding innovations. Tob Reporter 2017;9:28-30.

2 Thrasher JF, Islam F, Barnoya J, et al. Market share for flavour capsule cigarettes is quickly growing, especially in Latin America. Tob Control 2017;26:468-70.

3 Euromonitor International. Tobacco: Euromonitor Passport Database. London: Euromonitor International, 2018. www.euromonitor.com (accessed 5 August 2018)

$4 \quad$ Rossel S. Filter forum. Tob Reporter 2018;6:24-6.

$5 \quad$ Gray A. Investor day 2015. Marketing strategy; 2015. www.bat.com/group/sites/UK 9ZTFCM.nsf/vwPagesWebLive/DOA26JV7/\$FILE/0 4_Marketing_Strategy.pdf?openelement (accessed 15 August 2018)

$6 \quad$ Rossel S. Ready to Bloom. Tob J Intern 2017;3:42-5.

7 Tobacco Asia. Niche products become powerful weapons in sales revival. Tob Asia 2017;4:34-6.

8 Tobacco Asia. Flavor me this, flavor me that. Tob Asia 2017;5:46-52.

9 Glogan T. Something special on the end a stick. Tob J Intern 2017;3:99-102.

10 Booth JN. Heating up the flavours category. Tob J Intern 2018;3:88-9.

11 Moodie C, Thrasher J, MacKintosh AM, et al. Use of cigarettes with flavour capsules among smokers in the United Kingdom. Nicot Tob Res, forthcoming.

12 Cho YJ, Thrasher JF. Flavor capsule heat-sticks for heated tobacco products. Tob Control, forthcoming.

13 Stead M, Eadie D, Purves R, et al. Tobacco companies' use of retailer incentives after a ban on point-of-sale tobacco displays in Scotland. Tob Control 2018;27:414-9.

14 Bullen S. "Plain packaging touches every part of the business". Tob J Intern 2017;2:24-6.

15 Tobacco Journal International. Making pure filters. Tob J Intern 2017;3:94-7.

16 Scollo M, Bayly M, White S, Lindorff K, et al. Tobacco product developments in the Australian market in the 4 years following plain packaging. Tob Control 2018;27:5804.

17 Thrasher JF, Abad-Vivero EN, Moodie C, et al. Cigarette brands with flavour capsules in the filter: trends in use and brand perceptions among smokers in the USA, Mexico and Australia, 2012-2014. Tob Control 2016;25:275-83.

18 Emond JA, Soneji S, Brunette MF, et al. Flavour capsule cigarette use among US adult cigarette smokers. Tob Control, forthcoming.

19 White V, Williams T. Australian secondary school students' use of tobacco in 2014. Centre for Behavioural Research in Cancer: Cancer Council Victoria.

20 Moodie C, Ford A, Thrasher JF, et al. The power of product innovation: Smokers' perceptions of capsule cigarettes. Nicot Tob Res 2018;20:1157-60.

21 Wackowski O, Evans KR, Harrell MB, et al. In their own words: Young adults' menthol cigarette initiation, perceptions, experiences and regulation perspectives. Nic Tob Res 2018;20:1076-84.

22 Moodie C, Ford A, Mackintosh AM, et al. Are all cigarettes just the same? Female's perceptions of slim, coloured, aromatised and capsule cigarettes. Health Educ Res 2015;30:112.

23 Abad-Vivero EN, Thrasher JF, Arillo-Santillán E, et al. Recall, appeal and willingness to try cigarettes with flavour capsules: Assessing the impact of a tobacco product innovation among early adolescents. Tob Control 2016;25:e113-9.

24 European Commission. Directive 2014/40/EU of the European parliament and of the Council of 3 April 2014 on the approximation of the laws, regulations and administrative provisions of the Member States concerning the manufacture, 
presentation and sale of tobacco and related products and repealing Directive 2001/37/EC. Offic J European Union 2014;L127:1-38.

25 Canadian Cancer Society. Overview summary of federal/provincial/territorial tobacco control legislation in Canada; 2017.

http://convio.cancer.ca/documents/Legislative_Overview-Tobacco_Control-F-P-T2017-final.pdf (accessed 25 August 2018) 
Figure 1: Countries where market share of capsule cigarettes is greatest*

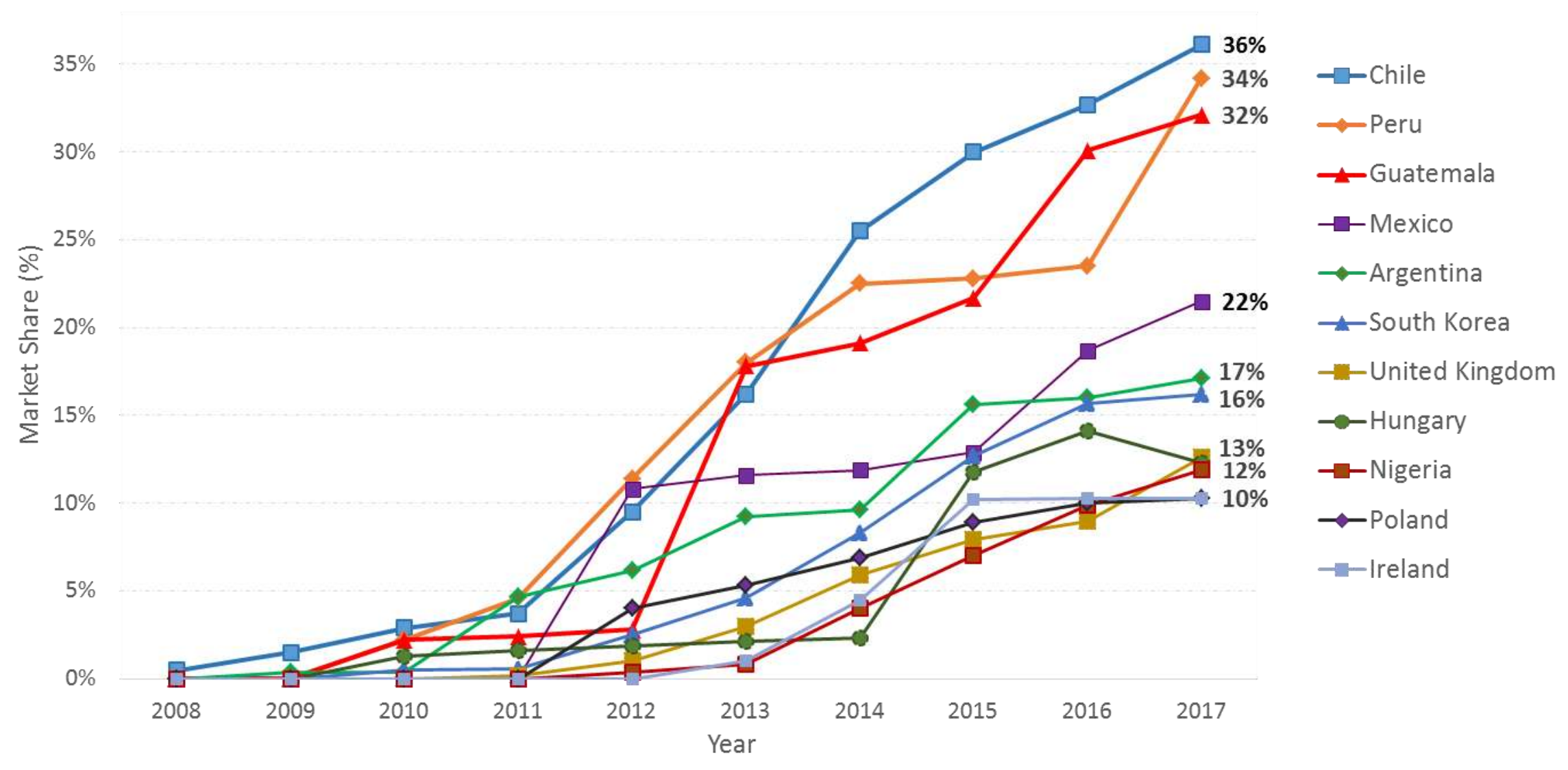

*Data from Euromonitor Reports. ${ }^{2,3}$ Other countries whose 2017 market share for flavour capsules is estimated to be over 5\% include Khazakstan (9.6\%), Costa Rica (8.4\%), Ukraine (8.2\%), Slovakia (7.8\%), Russia (7.6\%), Japan (7.3\%), Latvia (7.2\%), South Africa (7.1\%), Norway (7.1\%), and Sweden (6.0\%) 
Figure 2: Lucky Strike Click 4 Mix, containing four different flavoured capsules, and Africa Mola, containing five different flavoured capsules
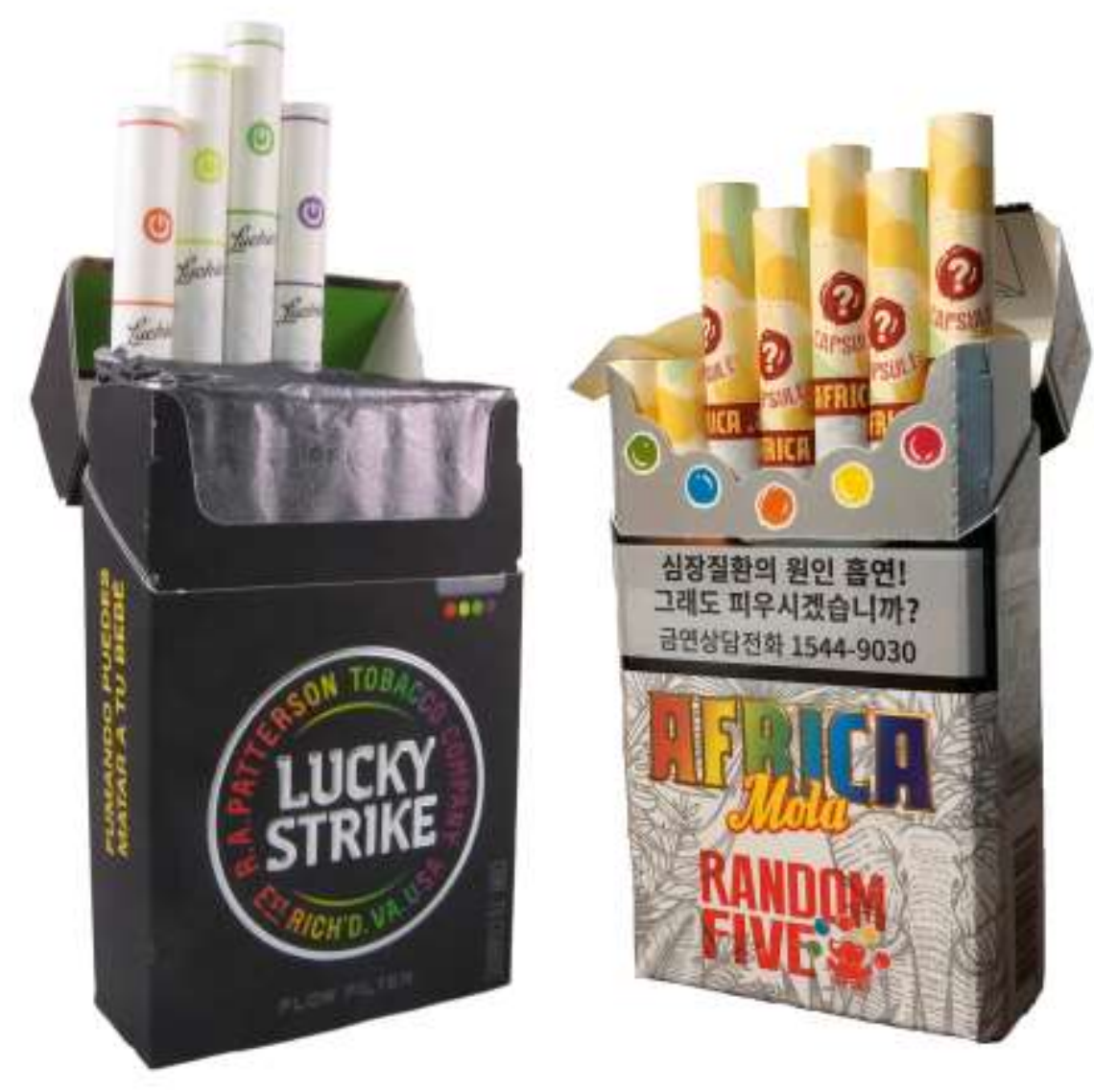
Figure 3: Capsule cigarettes promoted at point of sale in South Africa, 2018

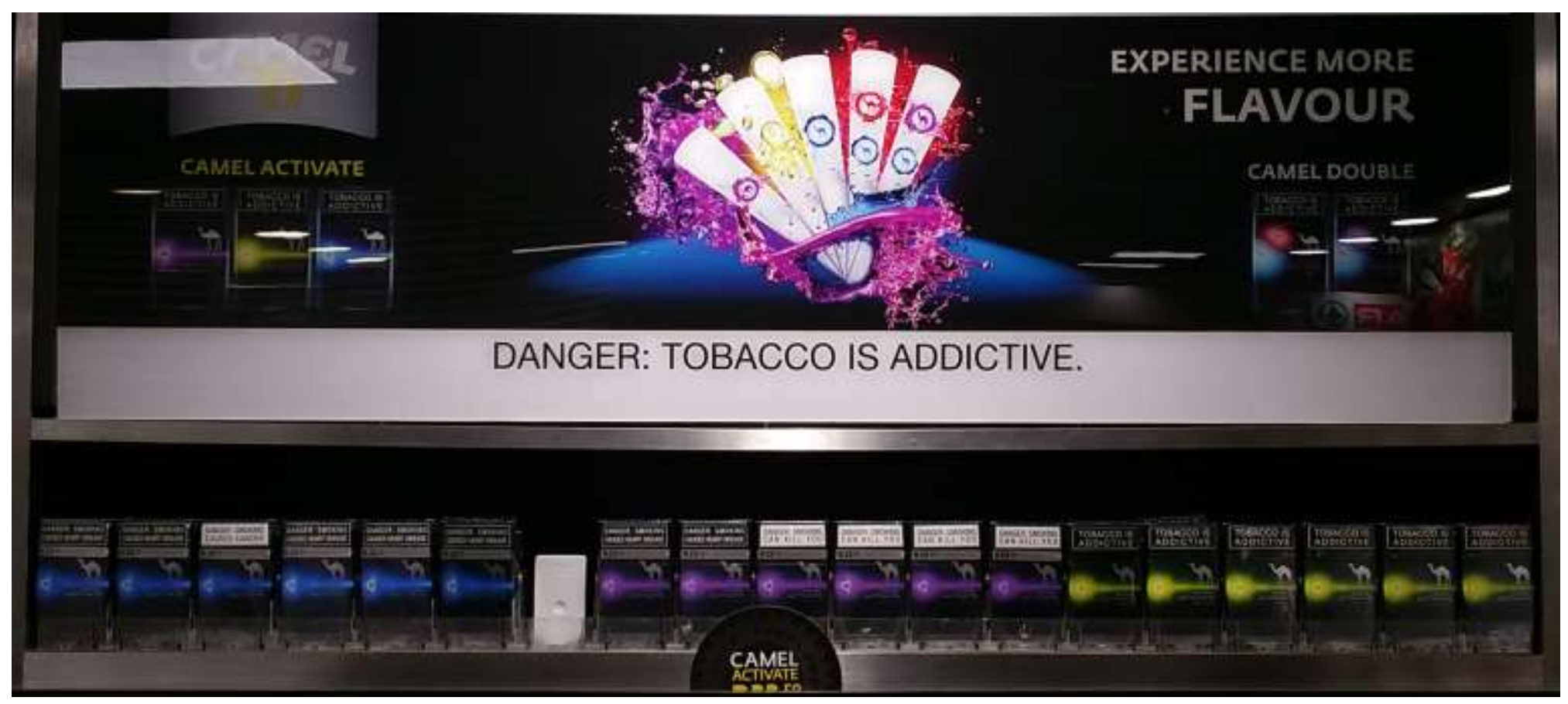

